Porcine L.D.H. could be demonstrated in the serum of each of the four patients (Fig. 3). The isoenzymes appeared within a few minutes of the beginning of perfusion and increased progressively in concentration, reaching a maximum at the end of the procedure (Fig. 3). Porcine fractions 1 to 4 were present, L.D.H. 2 and 3 being in greatest concentration (Fig. 3). In the two surviving patients the porcine isoenzymes persisted in the human serum in decreasing concentrations for 48 to 72 hours.

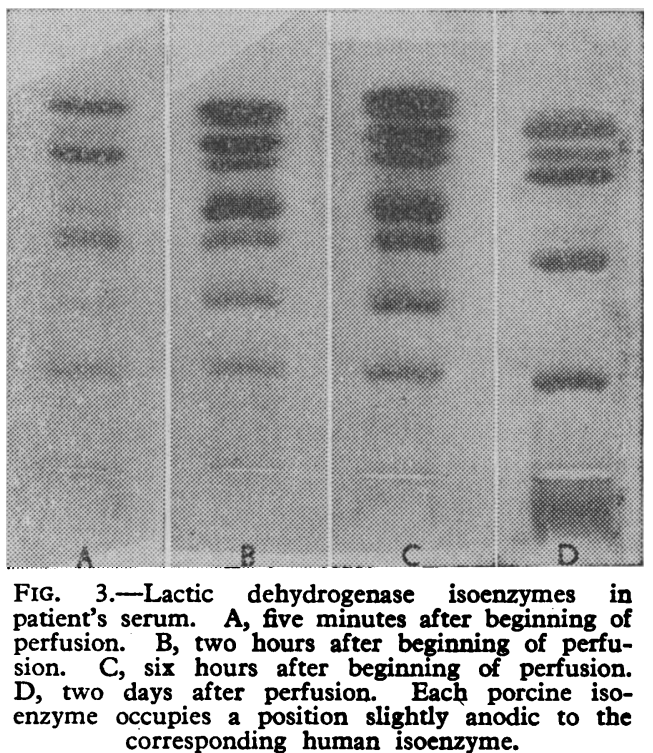

\section{Discussion}

The L.D.H. in human serum originates in several tissues, including the liver. In man all five fractions are found in the liver, but L.D.H. 5 is predominant (Vesell, 1961). The serum concentration of L.D.H. 5 in particular is greatly increased when liver cell damage occurs (Wieme and Van Maercke, 1961). In the pig, however, only L.D.H. 1 to 4 are found in the liver, though L.D.H. 5 is present in the serum. L.D.H. 2 and 3 are the predominant hepatic isoenzymes. The detection of porcine L.D.H. 1 to 4 in the serum of the patients during the perfusion and the fact that L.D.H. 2 and 3 were present in greatest concentration therefore indicates that the porcine isoenzymes originated from the liver cells and not merely from porcine plasma which had not been adequately removed from the liver. This conclusion is supported by the observation that the concentration of porcine L.D.H. increased progressively during the perfusion. It is apparent that some damage to the porcine liver cells had occurred and was responsible for the leakage of L.D.H. into the patient's serum. The process of porcine hepatectomy and subsequent flushing to remove traces of porcine blood is probably responsible for the initial injury, which would be ischaemic in origin. This initial damage is reflected by the early appearance of porcine L.D.H. in the patient's serum. The progressive increase in the concentration of the enzyme is probably due to damage incurred during the course of the perfusion, over and above the original injury. Other enzymes present in large quantities in pig liver cells will enter the patient's circulation for the same reasons.

Our observations re-emphasize the possibility of immune reactions developing against porcine substances entering the patient's circulation (Norman et al., 1966, 1967 ; British Medical fournal, 1967). So far no anaphylactic or other unfavourable immunological reactions have been reported in patients having repeated perfusions (Norman et al., 1966, 1967 ; van Wyk and Eiseman, 1966 ; Watts et al.; 1967). Nevertheless, these have been performed over relatively short periods of time (up to 18 days) and reactions may well develop when perfusions are repeated after longer intervals.

We wish to thank the Director and Deputy Director of the South African Institute for Medical Research, Professors J. H. S. Gear and J. F. Murray, for their interest in this study.

REFERENCES

British Medical fournal, 1967, 2, 332.

Liem, D. S., Waltuch, T. L., and Eiseman, B. (1964). Surgical Forum, 15, 90.

Norman, J. C., Hardison, W. G., and McDermott, W. V. (1967). Bulletin of the New York Academy of Medicine, 43, 967.

Norman, J. C., Saravis, C. A., Brown, M. E., and McDermott, W. V., jun. (1966). Surgery, 60, 179.

van Wyk, J., and Eiseman, B. (1966). South African Medical fournal, 40,

Vesell, E. S. (1961). Annals of the New York Academy of Sciences, 94, 877.

Watts, J. McK., Douglas, M. C., Dudley, H. A. F., Gurr, F. W., and Owen, J. A. (1967). British Medical Yournal, 2, 341.

Wieme, R. J., and Van Maercke, Y. (1961). Annals of the New York Academy of Sciences, 94, 898.

\title{
Assessment of Size of Small Volume Foeto-maternal Bleeds. A New Method of Quantification of the Kleihauer Technique
}

\author{
PETER JONES,* M.D., D.C.H.
}

Cummary : The risk of $\mathbf{R h}$-isoimmunization is probably related to the volume of foeto-maternal bleeding. With the Kleihauer technique foetal cells may be detected in maternal blood, but estimation of the size of foetal bleed the cells represent is at present difficult and open to serious error.

A new method of quantifying the technique by using a standard volume of maternal blood, and a simple machine for the preparation of comparable blood films, is described. The new method eliminates many of the errors of previous techniques, and should be capable of automation for large-scale screening programmes.

\section{Introduction}

Small foeto-maternal bleeds occur in nearly all pregnancies, but only rarely is the bleeding sufficient to cause severe anaemia of the newborn. "Small bleeds" represent a dilution factor of 1 foetal cell to 10,000-100,000 maternal red cells, and as little as $0.25 \mathrm{ml} .(1: 20,000)$ of rhesus-positive cells (Woodrow et al., 1965), or possibly less (Zipursky, 1966), may stimulate antibody formation in a rhesus-negative individual. Because the risk of rhesus isoimmunization is related to the size of foeto-maternal

\footnotetext{
- Department of Child Health, Royal Victoria Infirmary, Newcastle upon
} 
bleeds, it is necessary to establish an accurate and reproducible method of quantification.

At least until the 32nd week of gestation all haemoglobin in foetal red cells is of the foetal type ( $\mathrm{Hb} \mathrm{F}$ ). After the $32 \mathrm{nd}$ week the proportion of cells in the foetal circulation containing adult haemoglobin ( $\mathrm{Hb} \mathrm{A}$ ) increases, but even at term $\mathrm{Hb} \mathrm{F}$ is still the predominant haemoglobin in some $70 \%$ of foetal erythrocytes. The physiological level of $\mathrm{Hb} \mathrm{F}$ in normal adults is under $2 \%$ of total haemoglobin, and the $\mathrm{Hb} \mathrm{F}$ is usually distributed throughout a large number of red cells which also contain $\mathrm{Hb} \mathrm{A}$, so that it is extremely rare to find red cells containing only $\mathrm{Hb} \mathrm{F}$ in blood films from haematologically normal subjects. In patients with thalassaemia and certain other blood dyscrasias $\mathrm{Hb} F$ levels are raised and cells containing predominantly $\mathrm{Hb} \mathrm{F}$ occur ; in these patients assessment of foetal bleeding becomes especially difficult.

Because significant foeto-maternal bleeds may be very small they cannot be detected by measuring the total Hb F. However, Kleihauer et al. (1957) described a technique whereby erythrocytes containing predominantly $\mathrm{Hb} \mathrm{F}$ could be identified in blood films. In the technique fixed blood films are treated with a buffer of $p \mathrm{H} \mathrm{3.4-3.6}$ which causes denaturation of $\mathrm{Hb} \mathrm{A}$ but not of $\mathrm{Hb}$ F. Denatured $\mathrm{Hb} \mathrm{A}$ elutes from the adult red cells which appear as ghosts on microscopy. Foetal cells remain unaffected. Modifications to the original method have been suggested (Raper, 1964), but do not appear to offer any particular advantage.

The size of foetal bleeds has usually been estimated by counting foetal cells as a proportion of adult cells, but some workers have expressed their results as the number of foetal cells seen in a specified number of low-power fields (Woodrow and Finn, 1966), or as the number counted in standard time (Finn et al., 1961). Such methods are extremely inaccurate and subject to considerable observer errors.

We have therefore attempted to develop a more accurate and reproducible method for the assessment of size of foetal bleeds. The present communication describes and evaluates this method.

\section{Method}

The essential of the method is to produce a standard blood film for each blood sample. This is achieved by using a measured quantity of blood and preparing the film with a mechanical spreader.

\section{Preparation of Blood Film}

Capillary or venous blood is collected into heparin or edetic acid. The specimen may be stored at $4^{\circ} \mathrm{C}$. for four to five days, and is mixed carefully before use.

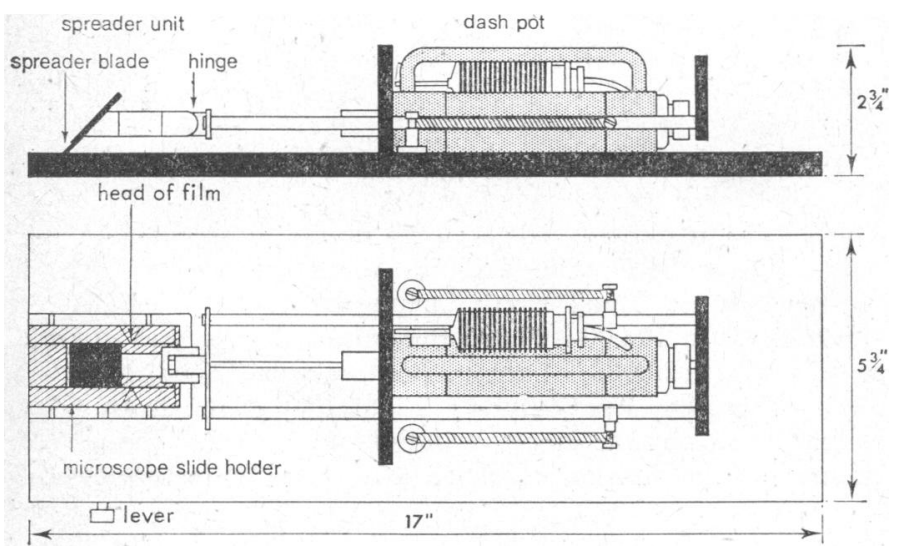

FIG. 1.-Diagram of semi-automatic film maker.
A 2-microlitre volume of blood is measured by means of a disposable Microcap Pipette (Drummond Scientific Company) and expelled on to a microscope slide. From this specimen a standard blood film is made by means of the semi-automatic film maker illustrated in Figs. 1 and 2. This apparatus consists of a device-the dash pot-which allows a piston to move forward smoothly and at a constant speed. The speed is controlled by oil which is forced round a bypass and through an adjustable valve. Differences in the volume of the piston within the cylinder are allowed for in an expansion chamber. Power is provided by two laterally placed springs. One-way valves in the piston head allow rapid withdrawal of the piston between strokes. A spreader unit containing a thin glass blade is attached to the forward end of the piston by a hinge joint.

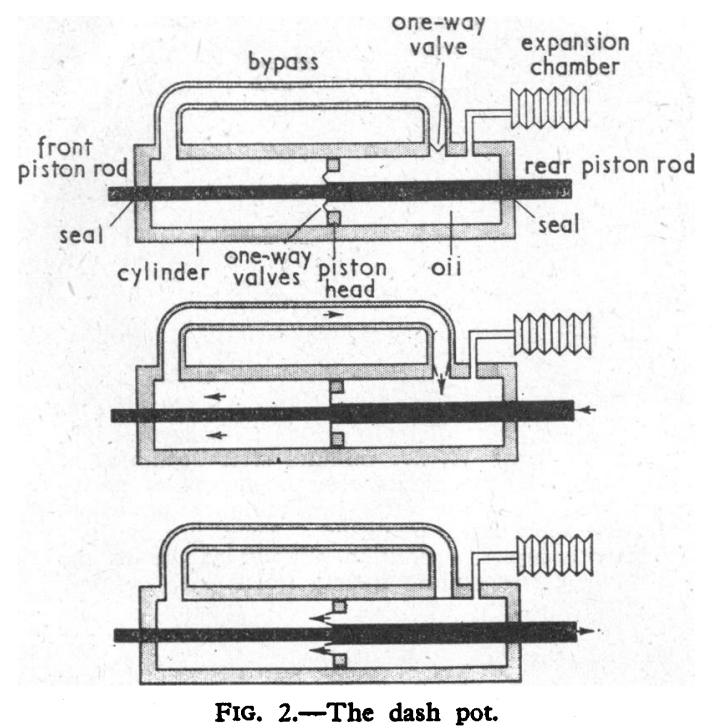

The microscope slide with the measured volume of blood is placed in the slide holder and the spreader unit lowered. The piston is pulled back until the spreader blade touches the specimen and is level with the arrows on the holder. The holder is sprung laterally and can be moved by a lever to aid the spread of blood along the rear of the blade. The piston is now released and the spreader unit moves forwards, drawing out a blood film behind it. The position of the head of the film and the angle and pressure between blade and microscope slide are the same for each film made.

\section{Sources of Error}

The blood specimen comes into contact with two surfaces, apart from that of the microscope slide. Microscopical examination of the capillary tubes shows that few cells remain adherent to the glass after expulsion of the blood, and that when a mixture of foetal and adult cells has been expelled neither type is trapped in a disproportionate number. The second surface is that of the spreader blade. Microscopy of this area, after elution, again shows no disproportionate number of either adult or foetal cells. We have been unable to measure accurately the volume of blood left on the blade, but from the results obtained with artificial mixtures (see below) think that this volume is constant enough not to affect the method of quantification. It is because of this error, however, that we have been reluctant to express our results in terms of foetal cells per cubic millimetre of maternal blood.

\section{Elution and Staining}

The blood film is fixed in methanol for two minutes, dried, and immersed in citric acid phosphate buffer of $\mathrm{pH} \mathrm{3.4-3.6}$ at 
$37^{\circ} \mathrm{C}$. for five minutes. Agitation of the film after one minute displaces air bubbles which otherwise interfere with elution. The film is washed in tap-water, dried, and immersed in Ehrlich acid haematoxylin for five minutes, washed in water, and immersed in $10 \%$ eosin for one minute. It is washed again and dried.

\section{Microscopy and Counting}

Films are screened under low power (magnification about $\times 80$ ). A thin layer of oil spread over the film before screening increases the refraction of foetal cells and enables the observer to identify them more easily. Any "doubtful" cells must be examined under the high-power oil-immersion lens (magnification about $\times 1,000$ ), because "intermediate cells," which retain some of the eosin stain in a patchy distribution, are easily confused with foetal cells at low magnification. These intermediate cells are not foetal in origin and are often found in films from non-pregnant adults.

The entire film is scanned, and all the foetal cells are counted. Adult cells are ignored. The actual area of the film is affected by the haematocrit and viscosity of the original sample. As the whole film is examined for foetal cells this relationship can be ignored, fluctuations in maternal cell volume being eliminated by reference to a standard graph (see below).

\section{Evaluation of Method}

\section{Distribution of Foetal Cells in Blood Film}

Foetal erythrocytes are larger than adult erythrocytes and might therefore be expected to be distributed in a blood film in a way similar to that of leucocytes. To test this hypothesis the positions of all foetal cells in five films were plotted on graph paper. The resultant map was divided into 12 equal areas and the number of foetal cells in each area counted (Table I).

\begin{tabular}{|c|c|c|c|c|}
\hline \multirow{3}{*}{ Head } & 20 & 26 & 34 & 36 \\
\hline & 7 & 22 & 26 & 51 \\
\hline & 17 & 29 & 34 & 36 \\
\hline
\end{tabular}

If it is assumed that the distribution of foetal cells is random (and this must be assumed by those workers who count only foetal cells for a set period of time, or in "well eluted areas of film"), the expected distribution would be regular, about the same number of cells $(338 \div 12=28)$ appearing in each area.

Comparison of the expected with the observed values shows that the actual distribution is significantly different from that expected at random $(P<0.0005)$. A similar uneven distribution of maternal cells was excluded by counting these cells in fields selected from different areas of the films. Subsequent observation of over 3,000 films in a study of foeto-maternal bleeding during pregnancy supported these findings.

In any estimate of the number of foetal cells present in a film it is therefore imperative either to examine the entire film or to make representative counts from each area.

\section{Study of Artificial Mixtures}

Compatible adult blood from a healthy blood donor and foetal blood from a baby of 32 weeks' gestation were used in the preparation of artificial mixtures of known dilution. Specimens from both the adult and the baby were first eluted and screened to confirm that no foetal type cells appeared in the adult blood films and that no ghost cells appeared in the foetal films. The mixtures were prepared by a senior technician, who checked the accuracy of his method with ${ }^{51} \mathrm{Cr}$ labelling of the foetal cells. The final dilutions were not known to the observers until all the films made from them had been screened and their foetal cell contents counted.

Ten films were made from each dilution. The results are shown in Table II.

\begin{tabular}{c|c|c}
\multicolumn{2}{c}{ TABLE II } \\
\hline $\begin{array}{c}\text { Dilution } \\
\text { Foetal Cell : Adult Cells }\end{array}$ & \multicolumn{2}{|c}{ No. of Foetal Cells } \\
\cline { 2 - 3 } & Range & Mean Count \\
\hline $1: 100,000$ & $3-9$ & $4 \cdot 5$ \\
$1: 80,000$ & $6-10$ & $8 \cdot 2$ \\
$1: 50,000$ & $11-23$ & $16 \cdot 8$ \\
$1: 40,000$ & $17-31$ & $23 \cdot 2$ \\
$1: 30,000$ & $27-40$ & $33 \cdot 4$ \\
$1: 20,000$ & $39-58$ & $46 \cdot 3$ \\
$1: 10,000$ & $46-81$ & $67 \cdot 0$ \\
$1: 5,000$ & $209-308$ & $262 \cdot 2$ \\
$1: 2,500$ & $897-1,519$ & $1,126 \cdot 2$ \\
$1: 500$ & $2,148-4,668$ & $3,716 \cdot 2$ \\
\hline
\end{tabular}

When the mean foetal cell counts for each standard dilution are plotted against dilution the result is a hyperbola. Such a curve is theoretically to be expected, the number of cells counted being proportional to the dilution. Log regression of the counts results in a straight line (Fig. 3). In an experiment conducted by the Medical Research Council Working Party on the use of anti-D gammaglobulin for the prevention of isoimmunization of $\mathrm{Rh}$-negative women by pregnancy in May 1967 several laboratories were asked to quantify the foetal cell content of five artificial mixtures. Observers were asked to estimate the ratio of foetal to adult cells. At the time of the experiment we were engaged in a prospective survey of foetomaternal bleeding during pregnancy, and all foetal cells in a blood film were being counted, the adult cells being ignored. The hyperbolic graph had not been prepared because the standard dilutions were still unknown to the observers.

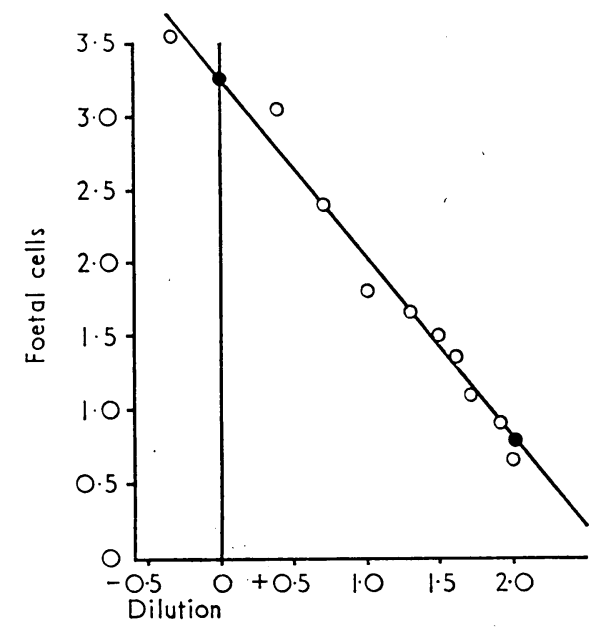

FIG. 3.-Log regression analysis of foetal cell/ dilution data.

In accordance with our method the total foetal cell content of each M.R.C. film was counted, and the results are shown in column 1 of Table III. We then made the error of attempting

\begin{tabular}{|c|c|c|c|}
\hline $\begin{array}{c}1 \\
\text { Foetal } \\
\text { Cell } \\
\text { Count }\end{array}$ & $\begin{array}{c}2 \\
\text { First } \\
\text { Estimated } \\
\text { Dilution } \\
\text { F.C. : A.C. }\end{array}$ & $\begin{array}{c}{ }^{3} \\
\text { Estimated Dilution } \\
\text { Hyperbola } \\
\text { Relationship } \\
\text { F.C. : A.C. }\end{array}$ & $\begin{array}{c}4 \\
\text { Actual } \\
\text { Dilution } \\
\text { (M.R.C.) } \\
\text { F.C. : A.C. }\end{array}$ \\
\hline $\begin{array}{r}8 \\
53 \\
71 \\
109 \\
1,106\end{array}$ & $\begin{array}{ll}1 & : 576,000 \\
1 & 96,000 \\
1 & : 68,000 \\
1 & : 46,000 \\
1 & : 4,400\end{array}$ & $\begin{array}{l:l}1 & : 80,000 \\
1 & 20,000 \\
1 & : 12,000 \\
1 & : 9,000 \\
1 & : 2,000\end{array}$ & $\begin{array}{l:l}1 & : 50,000 \\
1 & : 20,000 \\
1 & : 20,000 \\
1 & : 10,000 \\
1 & : 2,000\end{array}$ \\
\hline
\end{tabular}


to calculate the number of adult cells present in each film, and our reported dilutions are given in column 2 of Table III. Column 3 of Table III shows the results obtained when our cell counts are related to the hyperbola model, and the correlation of these dilutions with the actual M.R.C. dilutions (column 4) is acceptable.

\section{Evaluation of Foeto-maternal Bleeding}

An additional test of the accuracy of this method of quantification was provided by the opportunity to examine a series of films from a case of major acute foeto-maternal bleeding occurring shortly before delivery. Mother and baby were ABO compatible, and the baby, who was anaemic at birth, required a simple blood transfusion. The foetal cell counts are shown in Fig. 4. Extrapolation from the curve obtained as foetal cells disappeared from the maternal circulation gives a mean foetal cell life of 80 days, the generally accepted life-span of these cells (Pearson, 1967).

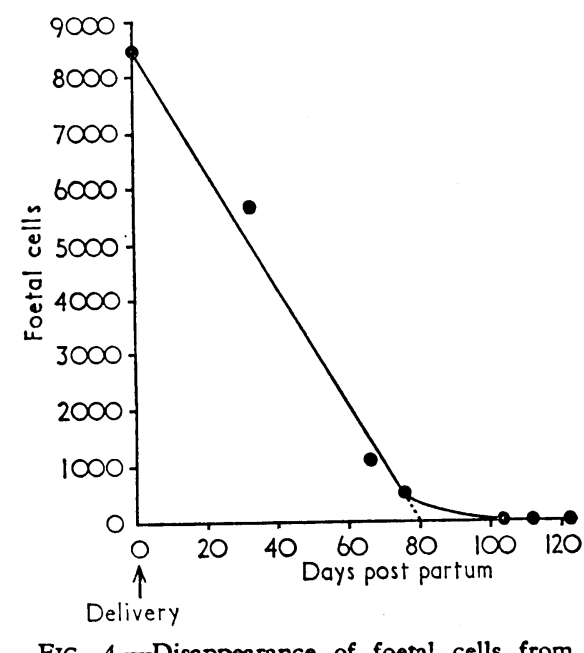

FIG. 4.-Disappearance of foetal cell
maternal blood after delivery.

\section{Discussion}

Estimation of the numbers of foetal cells present in maternal blood films is especially important at present because of their relationship to $\mathrm{Rh}$-isoimmunization, and is currently used in the study of this phenomenon and in the selection of patients for anti-D gammaglobulin in the Ministry of Health scheme.

The major difficulties are not so much in the colloction of specimens and the application of the Kleihauer technique but in the actual quantification of results. This is not surprising, as blood films prepared by different workers vary enormously in the amount of blood used and in the actual spreading of the film, so that areas can range in the number of cells present by a factor of 10 per field or more. Thick areas, with overlapping cells, may not elute properly, and if cells overlap evaluation becomes difficult if not impossible. The practice of counting only well-spread areas may introduce further subjective errors. Counts expressed as cells per unit time are obviously subject to great observer error, but so too are those expressed as counts per unit area, even when this is defined exactly rather than as 50 "low-power" fields. Expression of results in relation to the number of adult cells, while theoretically better, introduces additional factors, for in this method a large number of ghosted adult cells have to be counted or estimated. As these cells may be fragmented or difficult to see, this is extremely difficult and time-consuming, and observer fatigue must introduce further serious errors. Another factor, not previously taken into account, is that foetal cells may not be distributed randomly in the film; we have shown this in the present study.

The method described goes a long way to eliminate many of these errors. The volume of blood is measured accurately, and, though we appreciate that red cells are retained in the capillary tube and on the spreader blade, this is not a large volume and there is no preferential retention of foetal or adult cells. By means of a mechanical spreader uniform films can be prepared that are very suitable for elution by the Kleihauer technique.

Because the whole film is scanned and all the foetal cells are counted, the additional errors involved in the counting of adult cells are avoided. The number of foetal cells can be corrected to a dihution by reference to the standard graph. Fatigue is reduced and one observer can easily count 60 films a day.

The method should be capable of considerable automation for large-scale screening laboratories.

I wish to thank Dr. W. Walker for much advice and encouragement, and Mr. Angus McNay for statistical help. Mr. Robert Gillon, of the physics laboratory, Royal Victoria Infirmary, constructed the semi-automatic film maker. The artificial dilutions were prepared by Mr. Alan Oxley, senior technician, The films were prepared by Mrs. Ann Randall, technician, Attic Laboratory, Royal Victoria Infirmary. The diagrams were prepared in the department of medical illustration of the University of Newcastle upon Tyne.

The work reported formed part of a thesis submitted for the degree of Doctor of Medicine in the University of Newcastle upon Tyne. I am grateful for financial support from the Medical Research Council and the Research and Scientific Committee of the Royal Victoria Infirmary.

\section{REFERENCES}

Finn, R., et al. (1961). British Medical fournal, 1, 1486.

Kliehauer, E., Braun, H., and Betke, K. (1957). Klinische Wochenschrift, $35,637$.

Pearson, H. A. (1967). Fournal of Pediatrics, 70, 166.

Raper, A. B. (1964). Fournal of Medical and Laboratory Technology, 21, 287.

Woodrow, J. C., et al. (1965). British Medical fournal, 1, 279.

Woodrow, J. C., and Finn, R. (1966). British fournal of Haematology, 12, 297.

Zipursky, A. (1966). Paper read at the International Society of Blood Transfusion Congress, Sydney. 